BENTUK PERTUNJUKAN GURITAN PADA TRADISI PERNIKAHAN DI KOTA PAGARALAM

DedyFirduansyah, AbiKaroma Batubara

EKSISTENSI MUSIK KOLINTANG KAYU DALAM KEHIDUPAN PIKPP DI PT.PURSI PALEMBANG SUMATERA SELATAN

RIO EKA PUTRA

ESTETIKA TARI MELAJU DENGAN MUTU

Rully Rochayati, Treny Hera

KAJIAN SOSIOLOGI TARI KEBAGH DI MASYARAKAT DESA PENGANDONANKOTA PAGAR ALAMRANI CHINTIA SARI

KONTRIBUSI GURU SENI BUDAYA DALAM PENGEMBANGAN KREATIFITAS SISWA PADA PEMBELAJARAN SENI TARI

Naomi Diah Budi Setyaningrum

45

PENERAPAN METODE RESITASI DALAM PEMBELAJARAN NOTASI TARI PADA PROGRAM STUDI PENDIDIKAN SENDRATASIK UNIVERSITAS PGRI PALEMBANG

EfitaElvandari

PENGARUH METODE KERJA KELOMPOK PADA HASIL PEMBELAJARAN TARI TOPENG IRENG DI KELAS VIII SMP NEGERI 15 PALEMBANG

NEMI KAROLINA

PENGARUH MUSIK DANGDUTTERHADAP KECERDASAN EMOSI REMAJA SMPKELAS IX

NOVDALY FILLAMENTA

SITI RAFIAH SEBAGAI TOKOH PEREMPUAN PENGEMBAN PERISTIWA DALAM SYAIR ABDUL MULUK KARYA RAJA ALI HAJI

MOHAMMAD ARFANI

STRUKTUR KERUANGAN TARI REJANG RENTENG DALAM UPACARA PERSEMBAHYANGAN DI PURA PUSEH DESA KALIREJO KECAMATAN BELITANG II KABUPATEN OKU TIMUR

IWAYAN AYUNITA 


\title{
SITI RAFIAH SEBAGAI TOKOH PEREMPUAN PENGEMBAN PERISTIWA DALAM SYAIR ABDUL MULUK KARYA RAJA ALI HAJI
}

\author{
Oleh: \\ Mohammad Arfani
}

\begin{abstract}
ABSTRAK
Syair AbdulMuluk karya Raja Ali Haji ini merupakan sumber penceritaan dari teater tradisional Dul Muluk dan Bangsawan di Palembang. Permasalahan yang diangkat dalam makalah adalah Siti Rafiah sebagai tokoh perempuan pengemban peristiwa dalam syair Abdul Muluk yang memakai pendekatan struktural sebagai pendekatan objektif dengan tujuan untuk mengetahui bagaimana sosok perempuan sebagai tokoh sentral dalam penceritaan yang juga mengemban tanggung jawab atas keutuhan keluarga juga membangun kembali negeri yang ia cintai.
\end{abstract}

Kata Kunci:CeritaSyair Abdul Muluk.

\section{A. PENDAHULUAN}

Tidak dapat dipungkiri bahwa apresiasi sastra klasik terutama sastra nusantara sedang mengalami masa 'perputaran'. Era populer yang tentu saja tidak perlu selalu disalahkan membuat apresiasi tentang sastra dan teks sastra menjadi bacaan kalangan tertentu saja, hanya dipelajari di bangku-bangku sekolah dan ditambah lagi kelangkaan akan informasi yang mendalam tentang sastra nusantara nyaris menjadi bentuk yang asing di kebanyakan kaum muda saat ini. Haruslah digerakkan mulai sekarang tentang keberimbangan antara bentuk populer dan bentuk apresiasi.
Saya tidak ingin membentangkan keprihatinan sastra nusantara yang kian terpinggirkan. Tetapi saya melihat tentang perputaran itu sendiri mulai beranjak, tentu saja dikarenakan kebutuhan-kebutuhan bacaan, apresiasi, dan pencarian akan nilai agung yang tersirat didalam karya sastra nusantara yang mengandung sumber pembangunan mental, spiritual, dan bangsa tentunya. Untuk mengetahui lebih lanjut pengertian mengenai konsepsi tentang sastra nusantara itu sendiri.Secara etimologis kata sastra adalah kata serapan dari bahasa Sanskerta śāstra, yang berarti "teks yang mengandung instruksi" atau "pedoman", dari kata 
dasar śās-yang berarti "instruksi" atau "ajaran". Dalam bahasa Indonesiakata ini biasa digunakan untuk merujuk kepada "kesusastraan" atau sebuah jenis tulisan yang memiliki arti atau keindahan tertentu, dalam artian sesungguhnya sastra adalah sebuah ciptaan, sebuah kreasi bukan semata-mata imitasi. Sang seniman menciptakan dunia baru, meneruskan proses penciptaan didalam semesta alam, bahkan menyempurnakannya ${ }^{1}$. Dalam pengertian Nusantara adalah sebutan untuk wilayah kepulauan Indonesia². Lebih tegaskan tentang istilah Sastra Nusantara ini bahwa tinjauannya merangkum tentang kepengarangan penduduk nusantara, artinya penduduk asli Nusantara atau penduduk yang telah lama bermukim di Nusantara, hingga ia merasakan Tanah Airnya sendiri3. Istilah sastra nusantara digunakan untuk domain produk kebudayaan sastra yang dimiliki oleh bangsa Austronesia di Asia Tenggara dalan artian pemakaian bahasa melayu

1Luxemburg, Jan van, 1992, Pengantar IImu Sastra, hal; 9

2KBBI, 2005, hal. 789

3Hatta, Bakar, 1982, Sastra Nusantara Suatu Pengantar Studi Sastra Melayu, hal; 8 dan pengaruhnya sebagai bentuk komunikasi secara lisan dan tulisan.

Istilah Sastra Nusantara ini juga disebut Sastra Klasik, atau Sastra Melayu Klasik, dan juga Kesusastraan Rakyat yang menurut Liau Yock Fang sebagai sastra yang hidup ditengah-tengah rakyat ${ }^{4}$. Adapun contoh diantaranya adalah pantun (yang terdiri atas empat baris, bait pertama dan kedua berupa sampiran dan ketiga dan keempat berupa isi berpola abab), seloka (pantun berbingkai yang terdapat pengulangan baris pada paris berikutnya), gurindam (disebut sebagai sajak dua simetri), talibun (pantun yang jumlah baris tiap barisnya genap dan lebih dari empat baris), mantra (susunan kata yang berupa puisi mengandung rima dan irama yang dianggap mempunyai kekuatan ghaib), rubaiat (puisi lama yang berbentuk pantun yang berasal dari sastra Arab), kit'ah (puisi lama yang berasal dari arab yang berisi tentang nasihat bersifat mendidik), ghazal (puisi yang berasal dari Persia yang berisi tentang cinta dan kasih), masnawi (pusi lama dari Persia yang sisnya tentang pujian tentang tingkah laku yang mulia),

4Fang, Liau Yock, 1993, Sejarah Kesusastraan Melayu Klasik I, hal; 3 
nazam (puisi lama yang berasal dari Arab terdiri atas 12 larik), dan syair (puisi lama yang tersiri atas empat baris tiap bait, semua baris merupakan isi tidak ada sampiran dan berpola aaaa) 5 .

Bahasan dalam buku ini lebih tertuju pada kajian syair yaitu mengkaji tentang Syair Abdul Muluk karya Raja Ali Haji yang cukup terkenal dan pada tahun 1847 bukunya diterbitkan oleh pemerintah Belanda sebagai penghormatan terhadap beliau.Permasalahan yang diangkat dalam makalah adalah Siti Rafiah sebagai tokoh perempuan pengemban peristiwa dalam syair Abdul Muluk karya Raja Ali Haji.Penelitian bertujuan untuk mengetahui sosok Siti Rafiah sebagai tokoh perempuan pengemban peristiwa dalam ceritera syair Abdul Muluk karya Raja Ali Haji yang menjadi proyeksi kekuatan nilai kultur budaya Indonsia.

\section{B. METODE PENELITIAN}

Dalam tinjauan pustaka, Prof. Dr. Nurhayati, M.Pd dalam disertasinya di tahun 2014'Revitalisasi Seni Pertunjukan Dul Muluk Upaya Pemertahanan dan Implikasinya Dalam Pembelajaran Sastra'.

${ }^{5}$ Agustien S, Dra, Tim, 2006, Buku Pintar Bahasa dan Sastra Indonesia, hal ; 112-113
Oleh D. Suhendi dalam tulisannya di eprints.unsri.ac.id tentang Seni Pertunjukan Daerah Dul Muluk.Kemudian Randi Putra Ramadhan' ${ }^{6}$ menulis 'Bentuk Pertunjukan Teater Tradisional Sanggar Seni Harapan Jaya Kota Palembang Dalam Progam Bangsawan di TVRI SUMSEL BABEL Sebagai Upaya Pelestarian Teater Tradisional Sumtatera Selatan' 2014 Skripsi Universitas PGRI Palembang, dan masih banyak lagi tulisan artikel, penelitian yang membahas masalah pertunjukan Dul Muluk ini.Kesemuanya menulis tentang pertunjukan Dul Muluk, dan dalam makalah ini ditulis khusus tentang teks tentang naskah Syair Abdul Muluk yang menjadi acuan dalam kisah pertunjukan teater tradisional Dul Muluk Palembang.

Dalam studi sastra identik dengan masalah kebudayaan baik bentuk dan strukturnya.Pada setiap pendekatan apresiasi karya sastra banyak akademisi memakai pendekatan struktural.Pedekatan struktural sering juga disebut pedekatan objektif atau pendekatan formal, juga

6Randi Putra Ramadhan ini adalah anak dari Bapak Jonhar Saad Pimpinan Sanggar Seni Harapan Jaya Dul Muluk dan Bangsawan dan disiapkan untuk meneruskan tradisi pertujukan ini. 
disebut pendekatan analitik.Bertolak dari asumsi dasar bahwa karya sastra sebagai karya kreatif yang memiliki otonomi penuh yang harus dilihat sebagai salah satu sosok yang berdiri sendiri terlepas dari halhal lain yang berada diluar dirinya?.

Dalam bentuk kajian, maka yang harus dilihat adalah aspek yang membangun karya tersebut seperti tema, alur, latar, penokohan, gaya penunisan, gaya bahasa, serta hubungan harmonis antar aspek yang mampu membuatnya menjadi karya sastra. Sehingga hal yang berhubungan dengan sifat ekstrinsik seperti kepengarangan, pembaca, serta hubungan antar sosial budaya harus dikesampingkan karena tidak punya kaitan langsung pada struktur karya tersebut ${ }^{8}$.

\section{HASIL DAN PEMBAHASAN}

Syair Abdul Muluk karya Raja Ali Haji ini termasuk dalam karya sastra klasik nusantara dalam bentuk fiksi dari hasil olahan pengarang berdasarkan pandangan, tafsiran, dan penilaian tentang peristiwa-peristiwa yang pernah terjadi

7Semi, Atar, 1990, Metode Penelitian Sastra, hal: 67 8lbid. hal:67 yang berlangsung dalam hayalannya ${ }^{9}$.Fiksi juga disebut sebagai cerita rekaan, ialah cerita dalam olahan pengarang berdasarkan pandangan, tafsiran, dan penilaiannya tentang peristiwa yang pernah terjadi, ataupun pengolahan tantang peristiwa yang berlangsung dalam khayalannya.Akan tetapi walaupun dalam bentuk khayalan tentang apapun bentuk penceritaannya.Bisa dipastikan ide yang mengalir dalam kepengarangan itu pernah terjadi dan terlintas dalam pengarang itu sendiri, terutama dalam penceritaan Syair Abdul Muluk yang sangat kental dengan latar istana sentris.

Secara konsep tema mencakup persoalan dan tujuan yang ditulis oleh pengarang ${ }^{10}$. Tema yang diangkat adalah peristiwa yang atas segala pembelaan atas segala kebenaran tas segala tanggung jawab yang diemban oleh manusiamanusia yang diceritakan didalam syair ini.

Keterkaitan antar tokoh terjadi sangat jelas dan begitu kompleks dalam perjalanan cerita syair ini.pertentangan antara Bahauddin dengan seorang Saudagar Barbari yang kemudian

9Semi, Atar, 1987, Anatomi Sastra, hal: 31 10lbid, hal: 43 
disidangkan dihadapan Sultan Abdul Hamid Syah menjadi awal mula konflik cerita. Yang kemudian atas dijebloskan Bahauddin kedalam kurungan penjara membuat Sultan Negeri Hindi marah dan menyerang Negeri Barbari yang saat itu Negeri Barbari telah diperintah dimasanya Sultan Abdul Muluk.

Tentang tokoh yang dimaksudkan adalah struktur yang menggambarkan fisik dan mental secara bersama-sama membentuk suatu totalitas perilaku yang bersangkutan ${ }^{11}$.Banyak penokohan dan perwatakan cerita Abdul Muluk ini, tetapi beberapa tokoh sentral diceritakan utuh secara totalitas perilaku yang bersangkutan. Diantara penokohan di dalam syair ini seperti Sultan Abdul Hamid Syah, Sultan Abdul Muluk, Siti Rohmah, Bahaudin, Datuk Saudagar, Sultan Hindi dan sebagainya.

Banyak yang berprasangka Sultan Abdul Muluklah yang menjadi tokoh utama karena di cerita syair ini berjudul Syair Abdul Muluk, dan demikianlah keadaannya.Akan tetapi tokoh Siti Rafiah sebagai istri kedua Sultan Abdul Muluk

\footnotetext{
${ }^{11}$ Ibid, hal: 36
}

juga dapat dikatan sebagai tokoh sentral karena pengaruh penceitaan dalam syair ini sangatlah kuat.la merupakan tokoh yang mengalami perubahan sikap dan wataknya, dipengaruhi oleh perubahan peristiwa berdasarkan penceritaan yang disebabkan langsung bersinggungan dengan kejadian dan berkembang wataknya dari awal cerita karena dipengaruhi oleh lingkungannya. Boleh dikatakan cerita ini sangat terpengaruhi oleh sosok Siti Rafiah.

Penyerangan pasukan Raja Hindustan ke Negeri Barbari, yang selanjutnya pengembaraan Siti Rafiah dimulai dari pelariannya dihutan sampai pembalasan dendamnya ke Negeri Hindustan yang penuh duka dan kesengsaraan. Kemudian kerjasama dan diplomasi yang terjadi dinegeri Barham oleh Duri (nama samaran Siti rafiah) yang kemudian penaklukkannya ke Negeri Hindustan yang kemudian Siti Rafiah menjadi Sultan Duri Negeri Hindustan dan melepaskan Sultan Abdul Muluk dari tahanan. Kemudian Sultan Duri membongkar rahasianya sebagai Siti Rafiah.Terakhir kembalinya putera Sultan 
Abdul Muluk dan Siti Rafiah yaitu Abdul

Ghani ke orang tuanya.

Kedudukannya Siti Rafiah adalah sebagai Putri Sultan Negeri Ban yang dipersunting menjadi istri kedua Sultan Abdul Muluk.Sebelum kelahirannya ditandai dengan hujan dan badai selama satu minggu, dan ketika permaisuri melahirkan Siti Rafiah maka berhentilah hujan tersebut sampai membuat Sultan Negeri Ban terheran-heran. Siti Rafiah dapat dikatakan sebagai tokoh sentral karena mempenagruhi alur dalam cerita Syair Abdul Muluk karena; (pertama), la adalah tokoh yang mengemban peristiwa dalam setiap jalinan penceritaanya, (kedua), penceritaan lebih tertuju kepada tokoh Siti Rafiah, (ketiga), pengaruh tokoh Siti Rafiah dalam cerita syair ini sangatlah kuat. Dalam Syair Abdul Muluk ini12, sosok Siti Rafiah digambarkan sebagai berikut:

Rafiah elok tiada tertara

Paras seperti bidadari indera

Menghilangakn akal budi bicara

Umurnya belum remaja putera

${ }^{12}$ Sumber transliterasi kitab Syair Abdul Muluk milik Jonhar Saad, pimpinan Sanggar Seni Tradisional Dul Muluk dan Bangsawan Harapan Jaya Palembang
Rafiah menggertak kudanya segera

Parasnya elok tiada bertara

Seperti laki-laki yang perwira

Umurnya hampir remaja putera

Lakunya seperti muda bangsawan

Di atas kudanya ia berkendaraan

Melalui padang merapah hutan

Demikian itu kabarnya tuan

Dalam syair ini sosok Siti Rafiah adalah seorang yang cantik dan dangat menghormati suaminya Abdul Muluk.Karakter Siti Rafiah dalam Syair Abdul Muluk sangatlah kompleks dan menjadi karakter kunci dalam penceritaannya. Digambarkan ia dikaruniai keahlian bela diri yang didapatkannya disaat bertahan hidup di hutan dalam pelariannya dikejar pasukan Hindi. Diceritakan Siti Rafiah saat hamil muda berhasil membunuh 'binatang bersurai13' ketika bertahan hidup di tengah hutan, kemudian ia ditemukan seorang tuan Syeh dalam keadaan yang menyedihkan.

Ada banyak keahlian pada diri Siti Rafiah. Selain bela diri adalah menyamar

${ }^{13}$ Hewan Bersurai dianalogikan sebagai Harimau. 
sebagai laki-laki dengan memakai namaDuri, yang dilakukannya untuk menutupi identitas dirinya selama ia mengembara perlahan menuju negeri Hindi untuk menuntaskan dendamnya dan menyelamatkan suaminya. Kemudian ia digambarkan sebagai seorang yang pandai berdiplomasi, sampai Sultan Negeri Bahram percaya pada dirinya untuk bergabung dalam menaklukkan negeri Hindi sampai Sitti Rafiah didudukkan sebagai sultan disana dengan nama samaran Sultan Duri. Yang menarik adalah Sultan Duri ini dikawinkan oleh Sultan Bahram dengan adiknya Siti Rahatulhayani, walau diceritakan oleh pengarang mereka tidak tidur sekamar. Sampai suatu ketika identitas Sultan Duri ini diketahui sebagai Siti Rafiah, maka Siti Raha pun dikawinkan dengan Suaminya Raja Abdul Muluk.

Sebagaimana cerita dalam Syair Abdul Muluk keberadaan Siti Rafiah sangat kuat. Tokoh ini dijelaskan ketika dalam keadaan hamil sanggup bertahan hidup di tengah hutan atas kejaran pasukan Hindi, kemudian bertarung melawan hewan buas yang akan memangsanyayang kemudian saat ditemukan oleh Tuan Syeh dan memungutnya sebagi seorang murid dan anak angkatnya. Selanjutnya iapun belajar berbagai ilmu pengetahuan, berdiplomasi, termasuk cara bertahan hidup dan taktik berperang. Pada saatnya tiba, dengan segala usahanya Siti Rafiah bersama dengan orang-orang negeri Berham pun menyusul ke negeri Hindi menaklukkan dan menyelamatkan suaminya Sultan Abdul Muluk juga menyatukan kembali keluarganya yang tercerai-berai bahkan membangun kembali kerajaan Berbari.

Sesuai dengan ramalan Ahli Nujum kepada Sultan Ban menjelang kelahiran Siti Rafiah, bahwa ia akan menghadapi berbagai cobaan dan sangat taat kepada suaminya. Dan pda kitupan selanjutnya 'Setelah dilihat Sultan Barbari, Nyatalah rupanya Rafiah puteri', seakan ingin di gambarkan oleh pengarang mereka benar-benar telah melepaskan segala penderitaan dan duka akan lama tidak bertemu. Siti Rafiah sebagai tokoh yang dominan dalam cerita syair ini, sebagai sumber acuan penceritaan mengalami banyak penderitan sampai membalaskan dendam dan menyelamatkan suaminya, yang dalam ucapan ahli nujun tentang 'anakanda nin 
sangat besar tuahnya, sangat berkhidmad kepada suaminya..melepaskan suami daripada kesakitan'.

\section{SIMPULAN}

Dalam setiap jalinan penceritaanya, pengaruh tokoh Siti Rafiah dalam cerita syair ini sangatlah kuat. Kedudukannya Siti Rafiah adalah sebagai Putri Sultan Negeri Ban yang dipersunting menjadi istri kedua Sultan Abdul Muluk dikatakan sebagai tokoh pengemban peristiwa atau sebagai sebagi tokoh yang melaksanakan segala tugas dan kewajibannya sebagai seorang istri, dan mewujudkan cita-citanya dan membangun kembali keluarganya yang hancur tercerai-berai bahkan andil dan membangun kembali negeri Barbari yang luluh lantak akibat serangan dari kerajaan Hindi. Seperti dalam kutipan dialog pada Syair Abdul Muluk ${ }^{14}$ antara Siti Rafiah dengan tuan Syeh berikut:

Sitti Rafiah menjawab khabar Lakunya manis terlalu sabar Jikalau disampaikan Tuhan yang Kahar Hajat hamba terlalu besar

\footnotetext{
${ }^{14}$ Sumber transliterasi kitab Syair Abdul Muluk milik Jonhar Saad, pimpinan Sanggar Seni Tradisional Dul Muluk dan Bangsawan Harapan Jaya Palembang
}

Karena suami hamba nin tuan

Dikalahkan oleh raja Hindustan Jikalau ada mudah-mudahan

Sekarang hendak hamba balaskan

Tuan Syeh tertawa lakunya Lillah

Serta berkata Insya Allah

Berkat Nabi Muhammad Rasulullah

Hajatmu itu niscaya sampailah

Tiada dipanjang lagi perkataan

Oleh tuan Syeh Rafiah diajarkan

Daripada ilmu hikmat pakaian

Tipu peperangan hulubalang pahlawan

Barang yang ada di dalam dadanya

Kepada Rafiah diajarkannya

Sekalian itu diketahuinya

Rafiah pun suka rasa hatinya

Boleh jadi, Raja Ali Haji menulis Syair Abdul Muluk ini sebagai pesan yang menyangkut masalah keluarga dan keutuhannya bahkan tanggung-jawab dalam permasalahan membangun suatu negara pun bukan hanya dilaksanakan atau diwajibkan kepada laki-laki, tapi juga perempuan. 


\section{DAFTAR PUSTAKA}

Arfani, Mohammad, 2015, Inilah Syair Abdul Muluk Tentang Struktur dan Teks Karya Raja Ali Haji, Palembang: Komunitas Titik Awal

Bakar, Hatta. Drs, 1982, Sastra Nusantara Suatu Pengantar Studi Sastra Melayu, Jakarta: Ghalia Indonesia.

Baried, St. Baroroh, dkk, 1985, Memahami Hikayat Dalam Sastra Indonesia, Jakarta: Pusat Pembinaan dan Pengembangan Bahasa Departemen Pendidikan dan Kebudayaan.

Fang, LiauYock, 1993, Sejarah Kesusastraan Melayu Klasik I, Jakarta: Penerbit Erlangga.

Fang, LiauYock, 1993, Sejarah Kesusastraan Melayu Klasik II, Jakarta: Penerbit Erlangga.

Kitab Syair Abdul Muluk koleksi pribadi Bapak Jonhar Saad

Luxemburg, Jan van, 1992, Pengantar Ilmu Sastra, Jakarta: Gramedia.

Nurgiantoro Burhan, 1995, Teori Pengkajian Fiksi, Yogyakarta: Gajah Mada University Press.

Pradopo, Rahmat Joko, 2011, Beberapa Teori Sastra Metode Kritik dan Penerapannnya. Yogyakarta: Pustaka Pelajar.

Ramadhan, Randi. P, 2015, Bentuk Pertunjukan Teater Tradisional Sanggar Seni Harapan Jaya Kota Palembang Dalam Progam Bangsawan di TVRI SUMSEL BABEL Sebagai Upaya Pelestarian Teater Tradisional Sumtatera Selatan, Palembang, Skripsi Universitas PGRI.

Selden, Raman, 1993, Panduan Pembaca Teori Sastra masa Kini, Yogyakarta: Gadjah mada University Press.

Semi, M. Atar, 1990, Metode Penelitian Sastra, Bandung: Angkasa.

Semi, M. Atar, 1987, Anatomi Sastra, Padang: Angkasa Raya Sudjiman, Dr. Panuti, 1994, Filologi Melayu, Jakarta: Pustaka Jaya.

Teeuw, A, 1991, Membaca dan Menilai Sastra, Jakarta: Gramedia Pustaka Utama. 
